\title{
Competence, Consent and Complexity
}

CrossMark

Consent and competence are concepts central to medical ethics. When first heard of by medical or nursing students they may seem relatively clear and unambiguous in their requirements, and so, for many, even most everyday healthcare purposes, they are. But for medical ethics, like medicine itself, while 'what ought to be done' is often an instruction, it can also be a question, and not least when cases, circumstances, or conflicting judgements raise questions about consent or competence the implications of which are far from clear or unambiguous. Two areas in which such questions may arise, psychiatry and identity-changing medical interventions, provide the contexts in which some quite complex questions, about competence and consent respectively, are raised, and thoughtful answers are argued for, in this issue of the Journal of Medical Ethics.

Assessing whether a patient is or is not competent, has or lacks capacity to consent, is a familiar, but also weighty medical responsibility. Established medico-legal criteria commonly enable experienced clinicians to make such decisions with a clear professional conscience: but particularly in relation to chronic mental illness, for example anorexia nervosa or obsessive-compulsive disorder (OCD), matters may be less clear and deciding may be more difficult. Writing in this issue of the Journal, and taking OCD as an example, Guy Widdershoven, Andrea Ruissen, Anton van Balkom and Gerben Meynen (see page 374) examine three different approaches to assessing competence in such complex psychiatric circumstances: (1) the most familiar 'cognitive' approach, which 'focuses on the ability to express a choice, to reason about treatment options, to appreciate a situation and its consequences and to understand relevant information'; and then two approaches which seek to take greater account of the influence and coherence (2) of the patient's emotions and (3) of their values. While these approaches compensate for what the cognitive approach lacks, each is seen to have limitations of its own, and Widdershoven et al argue instead for a more comprehensive 'Practical Wisdom' approach which 'combines knowledge, emotions and values' and 'focuses on (1) knowing the right thing to do in the concrete situation, (2) having adequate emotions and (3) being able to find a balance between various values, and enact them in personal life.' Using this approach to assess the competence of patients with OCD, the authors found its conclusions to accord, more closely than those of each of the other three approaches, with retrospective judgements about their own competence made by the patients concerned and also by their psychiatrists. Practitioners faced with such difficult decisions thus may find this approach intuitively attractive and practically helpful.

In their commentaries however, Ema Sullivan-Bissett (see page 379) and Roger Crisp (see page 381) raise a number of philosophical considerations in favour respectively of the emotion-focused and cognitive approaches. In certain circumstances, they argue, these approaches may safeguard the autonomy of patients whose competence might otherwise be doubted or denied. In his response, Widdershoven (see page 382) emphasises 'that questioning a person's competence is not equal to declaring the person incompetent. Rather than establishing whether someone meets the criteria of (in)competence, psychiatrists should explore with their patients their reasons, emotions and values, and support them in developing a way of life in which they are properly integrated.' Clearly then, while the arguments of this paper move discussion of competence forward in ways that are constructive and potentially helpful in practice, they are not intended to substitute for careful and conscientious consideration, on a case-by-case basis, of these most difficult aspects of assessing competence.

For consent to be valid, not only must the person giving it be competent, but consent must also be informed. The subsequent question 'how informed is informed?' has proved difficult to answer in terms of a specific amount or kind of information always required, and has tended instead to be answered in procedural terms of eliciting (for example by open questions) what a prudent patient or the particular patient concerned needs and wishes to know. Demanding while this can be in practice however, a new and even more challenging layer of ethical difficulty has been identified by Karsten Witt (see page 384) in her essay concerning 'a kind of medical intervention that is at the same time fascinating and disturbing: identity-changing interventions', for example, 'deep brain stimulation... braintissue transplantation, facial allograft transplantation, organ transplantation, brain-computer interfaces, brain chips, neurosurgery and psychopharmacology'. The additional problem such radical medical interventions pose for informed consent, Witt argues, is that 'a person whose identity is altered changes not only with regard to certain core beliefs, attitudes or personality traits' but also 'with regard to how she evaluates or judges things'. A change in identity to which a person would have been willing to consent from their 'preintervention perspective', may be one which, from their 'postintervention perspective', they might regret, and to which they would have refused consent. Equally a change to which they would have refused consent from their 'preintervention perspective', may be one to which from their 'postintervention perspective' they would have been willing, even happy, to consent.

The problem, or series of problems which Witt elegantly dissects, arises from the assumption, commonly made, that 'the preintervention identity is always an appropriate vantage point for the assessment of identity changes': but that assumption fails to satisfy the requirements of informed consent because it fails to take into account crucial information about the implications of the postintervention perspective. This would not necessarily be a problem if the patient considers that 'the change in the relative weights of identity and quality of life is a change for the better': but if she considers it to be 'for the worse', the postintervention perspective cannot be ignored. In all cases of identity-changing medical interventions then, what is required for appropriately informed consent, Witt argues, is a 'perspective-sensitive' account in which quality of life pre and post intervention are each assessed from both perspectives, each of which are given equal weighting, but then finally 'the weight assigned to the identity change in the deliberative process is that which the patient endorses when 
considering her weighing preferences from her preintervention perspective'.

A variety of different perspectives on other familiar but complex issues in medical ethics are illustrated by a number of papers included in this issue. Bandini and colleagues (see page 353) report empirical evidence, from ethics committee consultations, that while religion can be central to conflict over life-sustaining treatment, it 'did not lead to increased treatment intensity or prolong time to death' in the context studied. Religion also plays a part in Stolz and colleagues' (see page 413) survey of attitudes of older Austrians on 'approval of assisted suicide and euthanasia when requested by an older severely-dependent person': those most likely to approve were 'non-religious individuals,' but also 'less trusting respondents and those concerned with constrictions associated with old age'. Also on the subject of assisted death, Rivera-Lopez (see page 401) argues persuasively for a proposition that others may well have from time to time entertained: that 'doctors (as members of the medical profession) have a special duty to provide medically assisted death to consenting terminally ill patients, because (and insofar as) they have been participants in the process leading to the situation in which a patient can reasonably ask to die'. And again writing about elderly people, but with living rather than dying, Preuß and Legal (see page 407) compare the advantages and disadvantages of the presence of companion animals as opposed to 'pet robots in senior living facilities and day service centers, particularly for individuals suffering from dementia'. While there 'are diverse medical reasons, as well as arguments from animal ethics, that support the use of pet robots, in contrast to living with live animals', the authors conclude, 'we should not lose sight of the option of living with animals at home as long as possible and in conformity with the well-being of the animal'.

Competing interests None declared.

Provenance and peer review Not commissioned; internally peer reviewed.

(c) Article author(s) (or their employer(s) unless otherwise stated in the text of the article) 2017. All rights reserved. No commercial use is permitted unless otherwise expressly granted. 